\title{
Irbesartan ameliorate inflammatory responses, and apoptosis induced by myocardial ischemia/reperfusion in male rats \\ ${ }^{* 1}$ Najah R. Hadi ${ }^{1}$;Fadhil G. Al-Amran ${ }^{2}$; Maitham G Yousif ${ }^{3}$; Suhaad T. Zamil ${ }^{1}$
}

\begin{abstract}
Myocardial ischemia-reperfusion (I-R) represents a clinically relevant problem associated with thrombolysis, angioplasty and coronary bypass surgery. This study was undertaken to investigate the potential role of Irbesartan in amelioration of myocardial I/R injury induced by ligation of coronary artery (LAD) in a rat model. We are pretreated the animals with Irbesartan $3 \mathrm{mg} / \mathrm{kg}$ i.p. 30 minutes before ligation of LAD. At the end of experiment ( $2 \mathrm{~h}$ of reperfusion), blood samples were collected from the heart for measurement of plasma level of cardiac troponin I (cTn-I). Compared with the sham group, levels of myocardial TNF- $\alpha$, IL-1 $\beta$, IL-6, MCP-1, MIP-1alpha, and plasma cTn-I were increased $(P<0.05)$. Histologically, all rats in control group showed significant cardiac injury. Furthermore, rats in control group showed significant apoptosis. Irbesartan significantly counteract the increase in myocardium level of TNF- $\alpha$, IL-1B, IL-6, MCP-1, MIP-1alpha, plasma cTnI and apoptotosis $(P<0.05)$. Histological analysis revealed that Irbesartan markedly reduced the severity of heart injury in the rats underwent LAD ligation procedure. We concluded that Irbesartan may ameliorate myocardial I/R injury in rats via interfering with inflammatory reactions and apoptosis which induced by I/R injury.
\end{abstract}

Keywords: Ischemia-Reperfusion; LAD; Irbesartan; Cytokines; Apoptosis

Corresponding Author: Najah Hadi:

${ }^{1}$ Department of Pharmacology and Therapeutics College of Medicine, Kufa University, Iraq

${ }^{2}$ Department of cardiovascular surgery College of Medicine, Kufa University

${ }^{3}$ College of science, Al-qadesiyah University

Received 02 March 2014; accepted 23 May 2014

Copyright (C) 2014 NH. et al. This is article distributed under the terms of the Creative Commons Attribution License (http://creativecommons.org/licenses/by/2.0), which permits unrestricted use, distribution, and reproduction in any medium, provided the original work is properly cited. 


\section{Introduction}

Ischemia/reperfusion injury describes the experimentally and clinically prevalent finding that tissue ischemia with inadequate oxygen followed by successful reperfusion initiates a wide and complex array of inflammatory responses that may aggravate local injury as well as induce impairment of remote organ function [1] . Ischemia-reperfusion injury results from several interdependent mechanisms, namely oxidative stress, intracellular calcium overload and hyper contracture, endothelial cell activation with micro vascular dysfunction and altered myocardial metabolism [2].

Ischemia-reperfusion injury prompts a release of oxygen free radicals, cytokines and other pro inflammatory mediators that activate both the neutrophils and the coronary vascular endothelium. Activation of these cell types promotes the expression of adhesion molecules on both the neutrophils and endothelium, which recruits neutrophils to the surface of the endothelium and initiates a specific cascade of cellcell interactions, leading first to adherence of neutrophils to the vascular endothelium, followed later by transendothelial migration and direct interaction with myocytes. This specific series of events is a prerequisite to the phenotypic expression of reperfusion injury, including endothelial dysfunction, micro vascular collapse and blood flow defects, myocardial infarction and apoptosis [3].

I-R injury may occur in a variety of clinical settings, including reperfusion after thrombolytic therapy, coronary angioplasty, organ transplantation, aortic crossclamping or cardiopulmonary bypass [4]. Adaptive cellular responses activate the innate immune system with its Tall-like receptors and the complement system as well as the adaptive immune system. This results in a profound inflammatory tissue reaction with immune cells infiltrating the tissue. The damage is mediated by various cytokines, chemokines, adhesion molecules, and compounds of the extracellular matrix. The expression of these factors is regulated by specific transcription factor with NF-kB being one of the key modulators of inflammation [5].

Apoptosis is another mechanism of myocardial injury associated with ischemiareperfusion injury, it seems that apoptotic cell death in the myocardium is initiated during ischemia, but the energy needed for the execution is provided during reperfusion [6] .cells undergoing apoptosis exhibit several typical features including shrinkage, cell membrane disruption, cytoskeletal rearrangement, nuclear 
condensation, and inter nucleosomal DNA fragmentation [7]. The degradation of DNA into fragments approximately 185 bp with its multiples in size is one of the best characterized biochemical features of apoptotic cell death which is used as the basis for the commonly used labeling techniques for detecting apoptotic cells [8].

Ang II is a key activator of reactive oxygen species(ROS) formation and oxidative stress in the cardiovascular system with the NADPH oxidase being a principal player ,Interestingly, AT1 blockade completely suppressed this increased NADPH oxidase activity in these mice consistent with the notion that Ang II-mediated activation of NADPH oxidase occurs via the AT1 receptors [9]. AngII-induced apoptosis can be blocked in post-infarcted, hypertrophied ventricular myocytes by AT1 blockers, but AT2 antagonists had no impact on these cellular events [10].

Irbesartan is selectively binds to the ANG-II receptor subtype 1, thereby inhibiting the activity of ANG-II. Irbesartan significantly ameliorated left ventricular ischemia and prevented the development of cardiac hypertrophy and fibrosis in Salt-loaded Dahl salt-sensitive hypertensive rats (DS rats). The benefits were associated with the attenuation of oxidative stress, normalization of myocardial capillary density and inhibition of capillary endothelial apoptosis [11].

\section{Method and materials}

\section{Animals}

A forty adult males Swiss Albino rat weighing 180-220 g were purchased from Animal Resource Center, the National Center for Drug Control and Researches. The animals were apparently healthy and they were housed in the animal house of College of Medicine/University of Kufa in a temperature-controlled $\left(24 \pm 2{ }^{\circ} \mathrm{C}\right)$ room with ambient humidity and alternating 12-h light/12-h dark cycles and were allowed free access to water and standard chow diet until the start of experiments. The rat was left for two weeks without interference for acclimatization. They had no manifestation of any illness upon examination. 


\section{In vivo myocardial I/R model}

The in vivo myocardial I/R model was modified from a previous study [12]. Briefly, rats were anesthetized with $100 \mathrm{mg} / \mathrm{kg}$ ketamine and $5 \mathrm{mg} / \mathrm{kg}$ xylazine [13]. The rats were intubated and Mechanical ventilation is then achieved by connecting the endotracheal tube to scientific ventilator (Harvard Model) at a respiratory rate 138 breath/minute with a tidal volume of $20 \mathrm{~mL} / \mathrm{kg}$ body weight [14]. A left thoracotomy was carried out to expose the heart. The LAD is then transiently ligated (or can be tied with a slipknot) using a 6-0 polyprolene suture for a 25-minute ischemic period [15]. After a 25-min ischemia, by Microsurgical scissors are used to cut the knot in the ligature (or by releasing the slipknot) the heart was reperfused for $2 \mathrm{~h}$. Immediately after finishing the reperfusion time the rat was sacrificed, starting by injection of high dose from ketamine and xylazine, after giving good time for the animal to go into deep anesthesia, the rat is positioned and the chest is opened in flap like manner revealing the heart then a needle of the syringe is introduced into right ventricle to aspirate around $2 \mathrm{ml}$ of blood for later plasma analysis. After that hearts were rapidly removed for quantification of myocardial injury and apoptosis and biochemical studies [16].

\section{Experimental groups and protocols}

After the two week of acclimatization the rats were randomized into 6 groups, 6 rates in each group as follow:

Sham group: rats underwent the same anesthetic and surgical procedures but without ligation of (LAD) coronary artery.

Control group: rats underwent myocardial ischemia for 25 minutes \& reperfusion fore $2 \mathrm{~h}$ by ligation of (LAD) coronary artery.

Control vehicle group: rats pretreated with normal saline (vehicle for Irbesartan) via i.p. rout and underwent myocardial ischemia for 25 minutes \& reperfusion fore $2 \mathrm{hr}$. by ligation of LAD coronary artery.

Irbesartan treated group: rats pretreated with Irbesartan $3 \mathrm{mg} / \mathrm{kg}$ [17] via intraperitoneal injection [18] at 30 minutes before ligation of LAD coronary artery [19].

Dissolve Irbesartan in normal saline (18) and given in a dose (3mglkg) via IP route at $30 \mathrm{~min}$ before occlusion of LAD, Irbesartan prepare immediately before injection. 


\section{Blood Sampling for measurement of plasma cTn-I}

At the end of reperfusion collect the blood from the apex of heart, about $2 \mathrm{ml}$ of blood was collected from the heart. The blood sample was placed in a tube containing disodium EDTA (22 mg/ml) as anticoagulant and mixed thoroughly then centrifuged at $3000 \mathrm{rpm}$ for $15 \mathrm{~min}$. Then it is used for the determination of plasma cTn-I.

\section{Tissue Preparation for measurement of (TNF $\alpha, I L-1 B, I L-6, M C P$-1and MIP-1 $\alpha$ )}

Cardiac tissues, collected 120 minutes after reperfusion were homogenized in a solution containing $1: 10(\mathrm{w} / \mathrm{v})$ phosphate buffered saline that contain $1 \%$ triton X-100 and protease inhibitor cocktail [20] by using high intensity liquid processor, After homogenization, samples were centrifuged at $14,000 \mathrm{rpm}$ for $20 \mathrm{~min}$ at $4^{\circ} \mathrm{C}$ [21] the supernatant was collected and used in TNF- $\alpha$, IL-1B, IL-6, MCP-1 and MIP-1 $\alpha$ measurement using commercially available ELISA kits (Signosis) according to the manufacturer's instructions.

\section{Histopathological analysis and damage score}

Tissues were fixed in $4 \%$ paraformaldehyde and embedded in paraffin. Sections were stained with hematoxylin and eosin for histological evaluation of tissue damage. In order to have a quantitative estimation of cardiac damage, sections ( $\mathrm{n}=6$ for each animal) were scored by 2 independent observers blinded to the experimental protocol. The following morphological criteria were considered: score 0 , no damage; score 1 (mild), interstitial edema and focal necrosis; score 2 (moderate), diffuse myocardial cell swelling and necrosis; score 3 (severe), necrosis with the presence of contraction bands and neutrophil infiltrate; and score 4 (highly severe), widespread necrosis with the presence of contraction bands, neutrophil infiltrate, and hemorrhage.

\section{Determination of myocardial apoptosis}

Myocardial apoptosis was based on the staining of condensed chromatin in apoptotic nuclei. Since chromatin condensation in compact masses is the most specific and definite hallmark of apoptosis. Procedure is based on the selective denaturation of DNA in apoptotic cells by formamide, and detection of denatured DNA with monoclonal antibody to single-stranded DNA (ssDNA). Formamide is a gentle agent 
that denatures DNA in apoptotic cells, but not in necrotic cells or in the cells with DNA breaks in the absence of apoptosis. The sensitivity of DNA in apoptotic cells to formamide is not related to DNA breaks, but rather reflects changes in chromatin associated with apoptosis, such as chromatin condensation and digestion of proteins stabilizing DNA. The assay includes attachment of cells to 96-well plates, treatment of attached cells with formamide, and staining of ssDNA in apoptotic cells with a mixture of primary antibody and peroxidase-labeled secondary antibody. The protocol based on the one-step detection of ssDNA with antibody mixture has higher sensitivity and lower number of steps than standard two-step immunostaining. This mixture is included in the kit in a ready to use form. The detection of apoptotic cells with formamide-mAb procedure is based on the staining of condensed chromatin in apoptotic nuclei. Since chromatin condensation in compact masses is the most specific and definite hallmark of apoptosis, this method provides universal detection of apoptosis. The apoptotic events that occur without DNA breaks or without activation of specific caspases will be detected with our mAb to ssDNA.

\section{Statistical Analysis}

Statistical analyses were performed using SPSS 20.0 for windows. lnc. Data were expressed as mean \pm SEM. Analysis of Variance (ANOVA) was used for the multiple comparisons among all groups followed by post-hoc tests using LSD method. The histopathological grading of heart changes is a non-normally distributed variable measured on an ordinal level of measurement; therefore non-parametric tests were used to assess the statistical significance involving this variable. The statistical significance of difference in total score between more than 2 groups was assessed by Kruskal-Wallis test, while Mann-Whitney U test was used for the difference between 2 groups. In all tests, $P<0.05$ was considered to be statistically significant. 

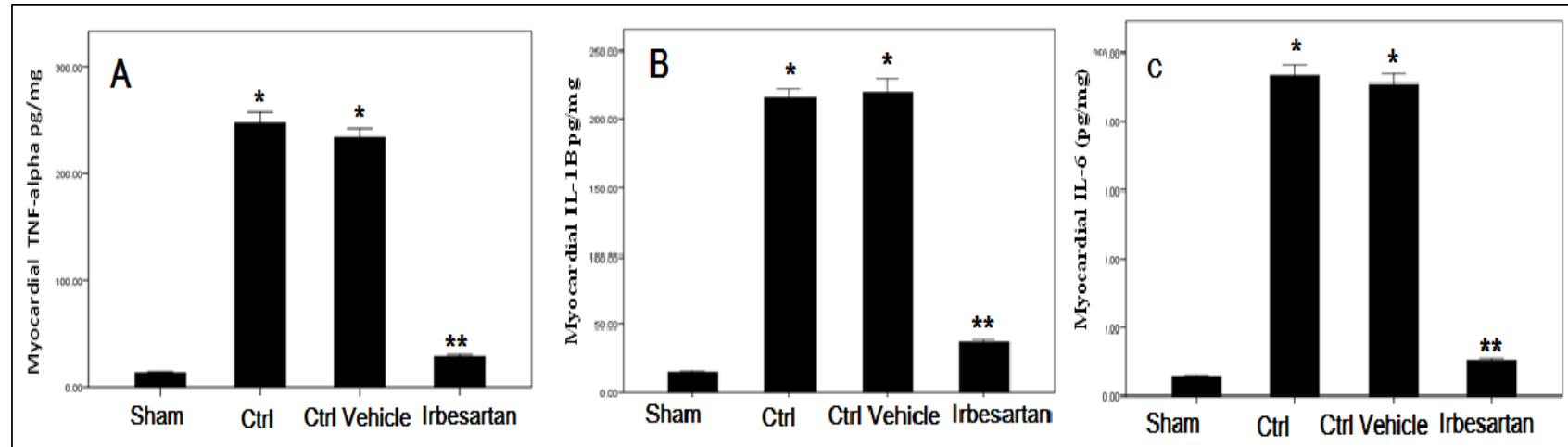

Figure 1.

\section{Cytokine levels}

Heart subjected to I-R showed increased the mean of myocardial TNF- $\alpha$ (A), IL-1 $\beta$ (B) and

IL-6 (C) (pg/mg) levels in the four experimental groups at the end of the experiment; ${ }^{*} P<0.05$ vs. Ctrl, ${ }^{* *} P<0.05$ vs. Ctrl vehicle.

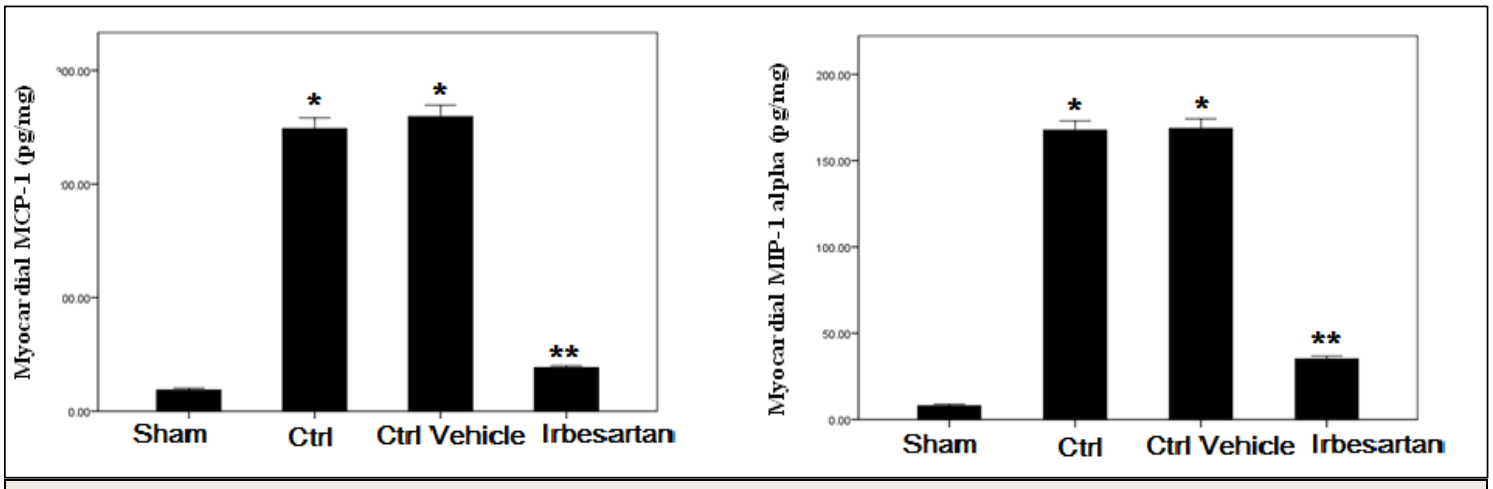

Figure 2.

\section{Levels of chemokine after myocardial I-R}

Heart subjected to I-R showed increased mean of myocardial MCP-1 and MIP-1alpha level ( $\mathrm{pg} / \mathrm{mg}$ ) in the four experimental groups at the end of the experiment; ${ }^{*} P<0.05 v s$. Ctrl, ${ }^{* *} P<0.05$ vs. Ctrl vehicle. 


\begin{tabular}{|c|c|c|c|c|c|c|c|c|}
\hline Categories & \multicolumn{2}{|c|}{ Sham } & \multicolumn{2}{|c|}{ Control $^{*}$} & \multicolumn{2}{|c|}{$\begin{array}{l}\text { Control } \\
\text { Vehicle }^{*}\end{array}$} & \multicolumn{2}{|c|}{ Irbesartan $^{* *}$} \\
\hline Normal & 6 & $100 \%$ & 0 & 0 & 0 & 0 & 1 & $16.7 \%$ \\
\hline Mild & 0 & 0 & 0 & 0 & 0 & 0 & 3 & $50 \%$ \\
\hline Moderate & 0 & 0 & 0 & 0 & 1 & $16.7 \%$ & 2 & $33.3 \%$ \\
\hline Sever & 0 & 0 & 4 & $66.7 \%$ & 4 & $66.7 \%$ & 0 & 0 \\
\hline Very Sever & 0 & 0 & 2 & $33.3 \%$ & 1 & $16.7 \%$ & 0 & 0 \\
\hline Total & 6 & $100 \%$ & 6 & $100 \%$ & 6 & $100 \%$ & 6 & $100 \%$ \\
\hline $\begin{array}{l}\text { Table } 1 . \\
\text { Heart subjecte } \\
{ }^{* *} P<0.05 \text { vs. C }\end{array}$ & icle & ed show & & histopa & 10 & scoring & $<0$. & vs. Ctrl, \\
\hline
\end{tabular}




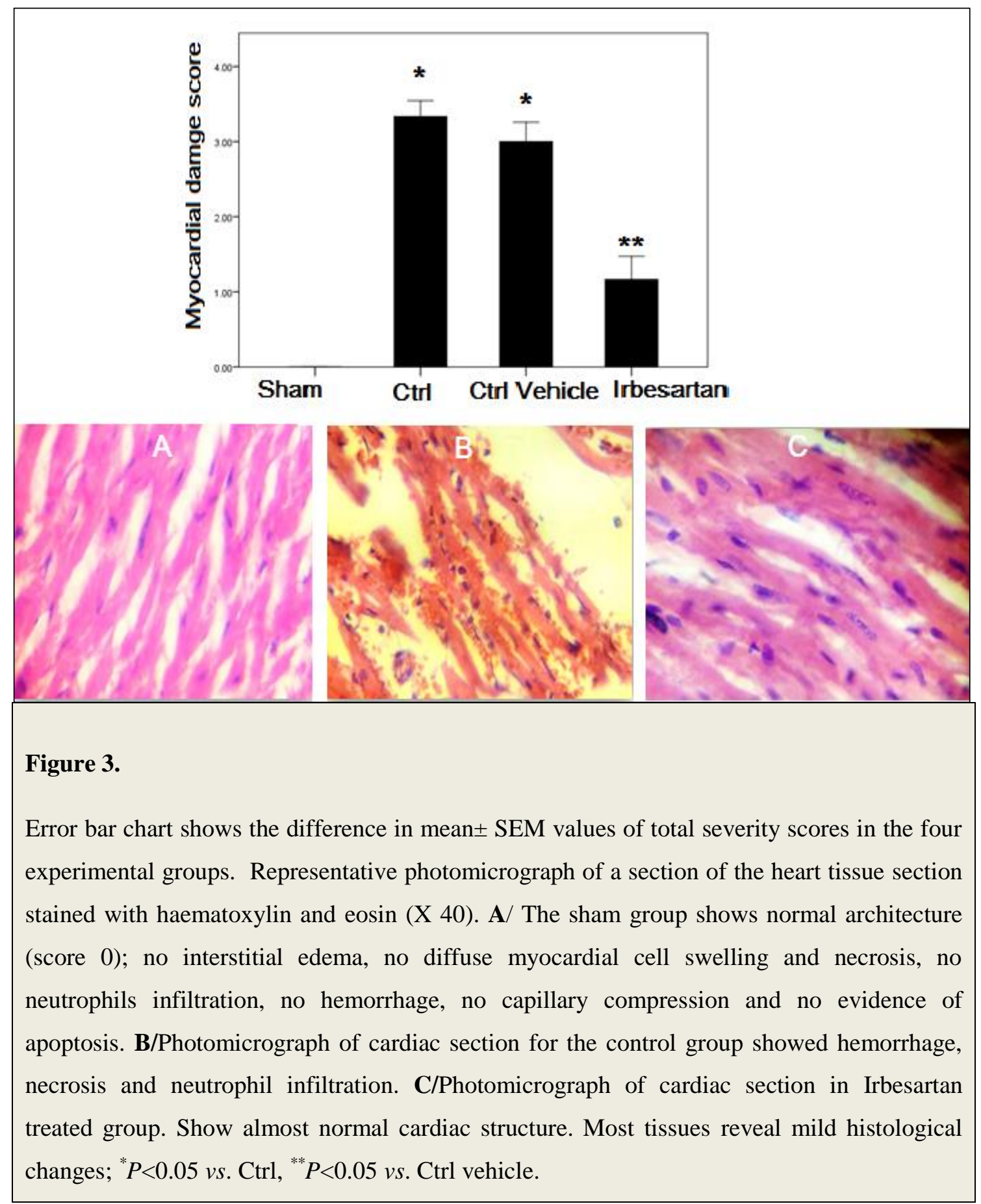




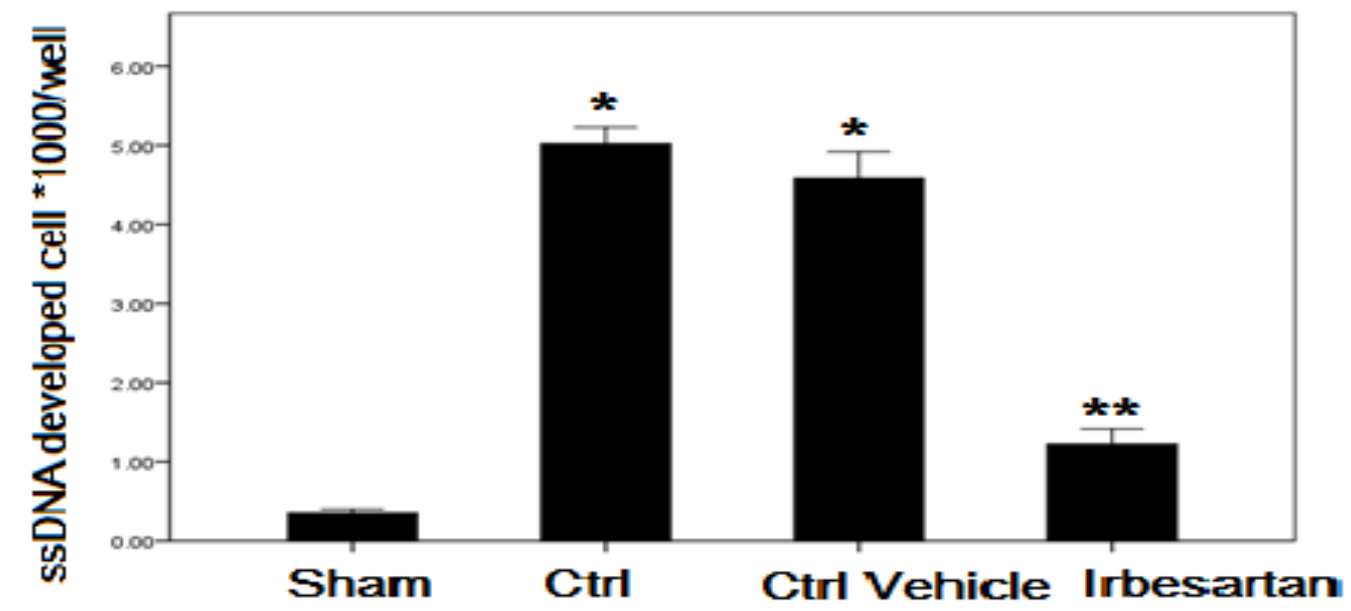

Figure 4.

Heart subjected to I-R showed increased the mean of ssDNA fragmentation (ss DNA developed cell *1000/well) in the four experimental groups at the end of the experiment; ${ }^{*} P<0.05$ vs. Ctrl, ${ }^{* *} P<0.05$ vs. Ctrl vehicle.

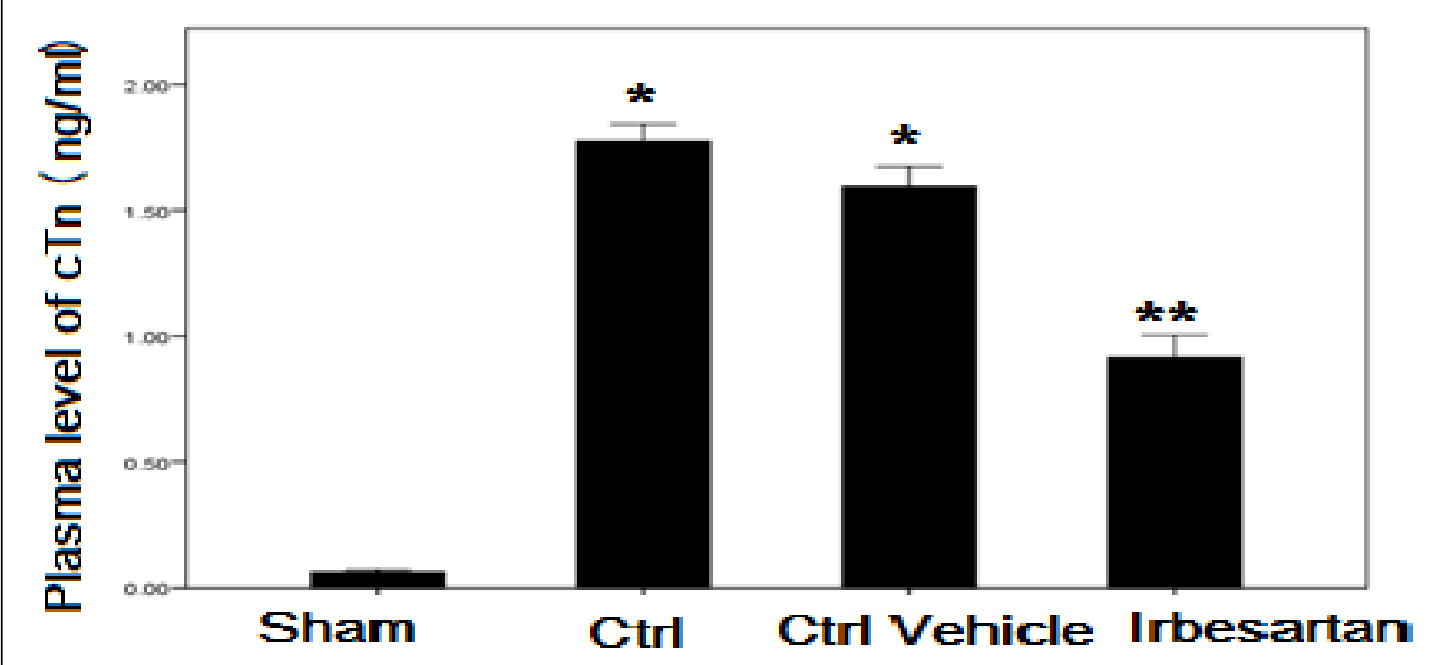

Figure 5.

Heart subjected to I-R showed increased the mean of cardiac troponin in the four experimental groups at the end of the experiment; ${ }^{*} P<0.05 v s . \mathrm{Ctrl},{ }^{* *} P<0.05 v s$. Ctrl vehicle. 


\section{Results}

Irbesartan reduced myocardial cytokines level following I-R injury

Myocardium levels of inflammatory cytokines following I-R were analyzed by ELISA. Shows that I-R injury increased significantly the levels of myocardium TNF$\alpha$, IL-1 $\beta$ and IL-6 as in (fig. 1A, B, C) compared with the sham group. In the Irbesartan treatment group, myocardium levels of TNF- $\alpha$, IL-1 $\beta$ and IL-6 were reduced significantly compared with the control group $(P<0.05)$.

\section{Irbesartan reduced chemokine following I-R injury}

Myocardium levels of inflammatory chemokine following I-R were analyzed by ELISA. I-R injury increased significantly the levels of myocardium MCP-1 and MIP1 alpha compared with the Sham group. While the Irbesartan treatment group, myocardium levels of MCP-1 and MIP-1 alpha were reduced significantly compared with the control group as in (fig. 2).

\section{Histological finding}

Treatment of rats with Irbesartan improved cardiac injury significantly as compared with control vehicle group and the total severity score mean of this group showed $16.7 \%$ of the group had no damage and $50 \%$ had mild cardiac injury and $33.3 \%$ had moderate cardiac injury. A cross section of sham rat's heart showed a normal cardiac structure as in (fig. 3). All rats in this group showed normal hearts $100 \%$ as shown in table (1).There was statistically insignificant difference between control vehicle (1) group (III) and control group (II) and the total severity scores of the control group showed $16.7 \%$ of the group had moderate cardiac injury, $66.7 \%$ had severe cardiac injury and $16.7 \%$ had highly severe cardiac injury.

\section{Irbesartan alleviated myocardial injury following I-R injury}

Substantial evidence suggests apoptosis plays a critical role in cardiomyocyte loss and subsequent development of cardiac dysfunction after I-R injury, the level of myocardial ssDNA fragmentation significantly decreases in Irbesartan treated group as compared with control group as in (fig. 4). Further, the level of cTn-I significantly reduced after treated with Irbesartan (fig. 5) 


\section{Discussion}

The major findings of the present study are as follows. Firstly, that the inflammatory cytokine (TNF- $\alpha$, IL-1 $\beta$, IL-6), chemokine (MCP-1, MIP-1 $\alpha$ ) and apoptosis play important role in the pathology of myocardial I-R Secondly, Irbesartan pretreatment played a protective role against myocardial I-R injury, the protective effects of Irbesartan during myocardial I/R injury were correlated with the attenuation of inflammation and apoptosis. Thirdly, Irbesartan ameliorate myocardial I/R injury as evidenced by reduce the release of cardiac specific enzyme troponin I and myocardial damage.

Coronary arterial occlusion due to thrombosis after atherosclerotic plaque rupture is the major cause of myocardial infarction. These acute events represent the leading cause of death worldwide. Early reperfusion is the best method to salvage the ischemic organ; however, it leads to additional damage known as reperfusion injury [22].The early reperfusion phase is characterized by enhanced release of ROS from endothelial cells and cardiomyocytes, as well as enhanced expression of cytokines and adhesion molecules, The enhanced expression of chemokines during the first hours of reperfusion triggers further recruitment of neutrophils and monocytes into the infracted myocardium which lead to increase the cardiac damage by further releasing ROS, inflammatory mediators and proteases [23].

Further, cardiac TNF-alpha was significantly reduced in myocardial infarction in rats receiving Irbesartan $(P<0.01)$ [24]. Moreover, Irbesartan improved residual LV end-diastolic pressure under both basal conditions and after volume overload $(P<0.01)$. Other study showed that treatment with Irbesartan and/or lipoic acid to patients with the metabolic syndrome improves endothelial function and is associated with statistically significant reductions in plasma levels of interleukin-6 and plasminogen activator-1 [25]. Furthermore, in recent data showed that blockade of AT1 receptors by Irbesartan treatment strikingly down-regulated the mRNA expressions of inflammatory cytokines MCP-1, IL1 $\beta$ and IL6 in aortas of WT mice while significantly up-regulated the protein and mRNA expression of ACE2 which has recently been identified as a specific Ang II-degrading enzyme but its role in vascular biology remains elusive [26]. 
Irbesartan are exerts more beneficial effects on ischemic brain damage with an MCP-1 receptor blocker, due to its inhibitory effects on MCP-1/CCR2 signaling beyond AT(1) receptor blockade [27]. Form other hand AT1 receptor antagonists stimulate nitric oxide release in rat platelets and HUVECs [28]. Increased nitric oxide release in the presence of AT1 receptor antagonists may decrease MCP-1 levels because nitric oxide has been shown to inhibit MCP-1production [29]. The potential cardiao-protective effect of Irbesartan against acute myocardial infarction induce in experimental model of metabolic syndrome \& their result showed decrease in MCP-1, MIP-1alpha as compared with un treated group [30].

To the best of our knowledge, there is no data available about effect of Irbesartan on cTn-I in regional ischemia reperfusion injury by ligation of LAD coronary artery. However, in study of other model showed that the AT-II blocker Irbesartan was able to reduce troponin I raise in experimental atrial fibrillation [31]. There is a strong correlation between intracellular Angiotensin II staining and Angiotensin II-induced apoptosis for all compared groups. He concluded that internalization of Angiotensin II is involved in apoptosis of vascular smooth muscle cells and they showed that The Angiotensin AT(1) receptor antagonist Irbesartan decreased Angiotensin II-mediated apoptosis which assessed by DNA fragmentation, cell cytometry and caspase-3 activity [32].

Many authors presented that Irbesartan, an AT1 receptor blocker, reduced the skeletal-myocyte apoptosis in an animal model of congestive heart failure, suggesting that angiotensin II-induced skeletal myocyte apoptosis too is mediated by the AT1 receptor [33]. The AT1 receptor antagonist was effective in reducing myocardial reperfusion injury in vivo. This effect can at least be partially attributed to the attenuation of cardiomyocyte apoptosis, and this anti-apoptotic effect appears to be related to the increased expression of Bcl-2 and alteration in MAP kinase signaling [34]. Some studied showed that the effect \& mechanism of Irbesartan on cardiac myocyte apoptosis in myocardial ischemia reperfusion injury with isolated rat hearts subjected to ischemia for 30 minutes followed by reperfusion for 60 minutes he concluded that Irbesartan can protect the heart from ischemic and reperfused injury by decreasing myocyte apoptosis [35].

In conclusion, this study reveal that Irbesartan may ameliorate myocardial $I / R$ injury in rats via interfering with inflammatory reactions and apoptosis which induced by I/R injury. 


\section{Competing interests}

The authors have declared that no competing interests.

\section{Author Contributions}

$\mathrm{NH}$ (corresponding author) was responsible for the study design, the statistical analysis and the writing of the manuscript. FA and SZ were involved in the execution of the measurements, design, and statistical analysis and editing of the manuscript. All authors read and approved the final manuscript.

\section{References}

1. Dorweiler B, Pruefer D, Andrasi TB, Maksan SM, Schmiedt W, Neufang A, et al. Ischemia-Reperfusion Injury. Eur J Trauma and Emerg Surg 2007; 33:600-12.

2. Anselmi A, Abbate A, Girola F, Nasso G, Biondi-Zoccai GG, Possati G, et al . Myocardial ischemia, stunning, inflammation, and apoptosis during cardiac surgery: a review of evidence. Eur J Cardiothorac Surg 2004; 25: 304-311.

3. Jordan JE, Zhao ZQ, Vinten-Johansen J. The role of neutrophils in myocardial ischemia-reperfusion injury. Cardiovasc Res 1999; 43(4):860-78.

4. Eltzschig HK, Collard CD .Vascular ischaemia and reperfusion injury. Br Med Bull 2004; 70:71-86.

5. Lutz J, Thurmel K, Heemann U. Ant inflammatory treatment strategies for ischemia/reperfusion injury in transplantation. $J$ Inflamm (Lond) 2010; 7:27

6. Zhao ZQ, Nakamura M, Wang NP, Wilcox JN, Shearer S, Ronson RS, et al. Reperfusion induces myocardial apoptotic cell death. Cardiovasc Res 2000; 45(3):651-60.

7. Kaufmann SH, Hengartner MO. Programmed cell death: alive and well in the new millennium. Trends Cell Biol 2001;11(12):526-34.

8. Nagata S. Apoptotic DNA fragmentation. Exp Cell Res 2000; 256(1):12-8.

9. Dworakowski R, Anilkumar N, Zhang M, Shah AM. Redox signaling involving NADPH oxidase-derived reactive oxygen species. Biochem Soc Trans 2006; 34:9604.

10. Leri A, Liu Y, Li B, Fiordaliso F, Malhotra A, Latini R, et al. Up-regulation of AT(1) and $\mathrm{AT}(2)$ receptors in postinfarcted hypertrophied myocytes and stretch-mediated apoptotic cell death. Am J Pathol 2000; 156(5):1663-72. 
11. Nako H, Kataoka K, Koibuchi N, Dong YF, Toyama K, Yamamoto E, Yasuda O, Ichijo H, Ogawa H, Kim-Mitsuyama S. Novel mechanism of angiotensin II-induced cardiac injury in hypertensive rats: the critical role of ASK1 and VEGF. Hypertens Res 2012; 35(2):194-200.

12. Wu Y, Yin X, Wijaya C, Huang MH, McConnell BK. Acute myocardial infarction in rats. J Vis Exp 2011;16(48): 2464.

13. Wiedemann D, Schneeberger S, Friedl P, Zacharowski K, Wick N, Boesch F, et al. The fibrin-derived peptide-B beta (15-42) significantly attenuates ischemiareperfusion injury in a cardiac transplant model. Transplantation. 2010; 89(7):824-9.

14. Ding JW, Tong XH, Yang J, Liu ZQ, Zhang Y, Yang J, Li S, Li L. Activated protein $\mathrm{C}$ protects myocardium via activation of antiapoptotic pathways of survival in ischemia-reperfused rat heart. $J$ Korean Med Sci. 2010; 25(11):1609-15.

15. Wayman NS, Ellis BL, Thiemermann C. Simvastatin reduces infarct size in a model of acute myocardial ischemia and reperfusion in the rat. Medical Science Monitor 2003; 9(5):BR155-159.

16. Zingarelli B, Salzman AL, Szabo C. Genetic disruption of poly (ADP-Ribose) synthetase inhibits the expression of P-selectin and intercellular adhesion molecule-1 in myocardial ischemia/reperfusion injury. Circ. Res 1998; 83: 85-94.

17. Huang Z, Jansson L, Sjöholm A. Vasoactive drugs enhance pancreatic islet blood flow, augment insulin secretion and improve glucose tolerance in female rats. Clin Sci (Lond) 2007; 112(1):69-76.

18. Whaley-Connell A, Nistala R, Habibi J, Hayden MR, Schneider RI, et al. Comparative effect of direct renin inhibition and AT1R blockade on glomerular filtration barrier injury in the transgenic Ren2 rat. Am J Physiol Renal Physiol 2010; 298(3):F655-61.

19. Preckel B, Schlack W, Gonzàlez M, Obal D, Barthel H, Thämer V. Influence of the angiotensin II AT1 receptor antagonist Irbesartan on ischemia/reperfusion injury in the dog heart. Basic Res Cardiol 2000; 95(5):404-1.

20. Austin EW, Yousif NG, Ao L, Cleveland JC, Fullerton DA, Meng X. Ghrelin reduces myocardial injury following global ischemia and reperfusion via suppression of myocardial inflammatory response. American journal of BioMedicine 2013;1(2): 3848.

21. Granado M, Fernández N, Monge L, Figueras JC, Carreño-Tarragona G, Amor S, García-Villalón AL. Effects of coronary ischemia-reperfusion in a rat model of early over nutrition. Role of angiotensin receptors. PLoS One 2013;8(2):e54984. 
22. Tuma RF, Steffens S. Targeting the endocannabinod system to limit myocardial and cerebral ischemic and reperfusion injury. Curr Pharm Biotechnol 2012; 13(1):46-58.

23. Steffens S, Montecucco F, Mach F. The inflammatory response as a target to reduce myocardial ischaemia and reperfusion injury. Thromb Haemost 2009; 102(2):240-7.

24. Berthonneche C, Sulpice T, Tanguy S, O'Connor S, Herbert JM, Janiak P, et al. AT1 receptor blockade prevents cardiac dysfunction after myocardial infarction in rats. Cardiovasc Drugs Ther. 2005;19(4):251-9.

25. Sola S, Mir MQ, Cheema FA, Khan-Merchant N, Menon RG, Parthasarathy S, et al Irbesartan and lipoic acid improve endothelial function and reduce markers of inflammation in the metabolic syndrome: results of the Irbesartan and Lipoic Acid in Endothelial Dysfunction (ISLAND) study. Circulation 2005; 111(3):343-8.

26. Jin HY Song B, Oudit GY, Davidge ST, Yu HM, Jiang YY, et al. ACE2 deficiency enhances angiotensin II-mediated aortic profilin-1 expression, inflammation and peroxynitrite production. PLoS One 2012;7(6):e38502.

27. Tsukuda K, Mogi M, Iwanami J, Min LJ, Jing F, Oshima K, et al. Irbesartan attenuates ischemic brain damage by inhibition of MCP-1/CCR2 signaling pathway beyond $\mathrm{AT}_{1}$ receptor blockade. Biochem Biophys Res Commun 2011; 409(2):275-9.

28. Kalinowski L, Matys T, Chabielska E, Buczko W, Malinski T. Angiotensin II AT1 receptor antagonists inhibit platelet adhesion and aggregation by nitric oxide release. Hypertension 2002; 40(4):521-7.

29. Tsao PS, Wang B, Buitrago R, Shyy JY, Cooke JP. Nitric oxide regulates monocyte chemotactic protein-1. Circulation 1997; 96(3):934-40.

30. Di Filippo Clara, Lampa Enrico ,Martella Rafaelle et al. Effect of Irbesartan on the myocardial ischemia/reperfusion injury in ZDF rats with metabolic syndrome. FASEB J 2000; 1867-69.

31. Goette A, Bukowska A, Dobrev D, Pfeiffenberger J, Morawietz H, Strugala D, et al . Acute atrial tachyarrhythmia induces angiotensin II type 1 receptor-mediated oxidative stress and microvascular flow abnormalities in the ventricles. Eur Heart $J$ 2009; 30:1411-1420.

32. Ruiz E, Redondo S, Padilla E, Gordillo-Moscoso A, Salaices M, Balfagón G, et al .Importance of intracellular angiotensin II in vascular smooth muscle cell apoptosis: inhibition by the angiotensin AT1 receptor antagonist Irbesartan. Eur J Pharmacol 2007; 567(3):231-9.

33. Dalla Libera L, Ravara B, Angelini A, Rossini K, Sandri M, Thiene G, et al .Beneficial effects on skeletal muscle of the angiotensin II type 1 receptor blocker Irbesartan in experimental heart failure. Circulation 2001; 103(17):2195-200. 
34. Preckel B, Schlack W, Gonzàlez M, Obal D, Barthel H, Thämer V. Influence of the angiotensin II AT1 receptor antagonist irbesartan on ischemia/reperfusion injury in the dog heart. Basic Res Cardiol 2000; 95(5):404-12.

35. Zhang $\mathrm{J}$, et al. Inhibition of the activity of Rho-kinase reduces cardiomyocyte apoptosis in heart ischemia/reperfusion via suppressing JNK-mediated AIF translocation. Clin Chim Acta 2009; 401: 76-80. 